\title{
A EVICÇÃO DE BENS ADQUIRIDOS EM HASTA PÚBLICA E A RESPONSABILIDADE SOBRE SEUS RISCOS ${ }^{1}$
}

\author{
Maiara Amaral dos Santos ${ }^{2}$
}

\begin{abstract}
RESUMO: A eviç̧ão é uma figura jurídica admitida desde o direito romano. Porém a responsabilidade, diante de sua ocorrência em aquisições como a arrematação, sempre foi questão cabível de várias alterações e divergências ao longo do tempo. Geralmente atrelada aos contratos onerosos, sua ocorrência em aquisições através de hasta pública foi positivada apenas no Novo Código Civil no ordenamento jurídico brasileiro. Apesar disso, os questionamentos a respeito da atribuição de responsabilidade em tais alienações continuam admitindo diferentes entendimentos de acordo com as correntes teóricas seguidas Estas, trazem alienante, adquirente e Estado, assumindo diferentes papéis, e com base nisso imputam suas responsabilidades. Partindo das divergências apresentadas é que se propõe o presente artigo, que objetiva discutir o tema.
\end{abstract}

PALAVRAS-CHAVE: Evicção, Responsabilidade, Arrematação.

\section{The Eviction of Possessions Acquired in Auction and the Responsibility on its Risks}

\begin{abstract}
The eviction is an admitted legal figure since the Roman law. However the responsibility, in front of its occurrence in acquisitions as the buying in sale, always was an appropriate question of some alterations and divergences throughout the time. Generally linked to onerous contracts, its occurrence in acquisitions through auction was regulated only in the New Civil Code in the Brazilian legal system.

Although this, the questionings regarding the attribution of responsibility in such alienations continue admitting different agreements, in accordance with the followed theory. These, present alienator, buyer and State, assuming different tasks, and based on this impute their responsibilities.

To discuss the present divergences is the objective of this article.
\end{abstract}

KEY-WORDS: Eviction, Responsibility, Buying in sale.

\section{INTRODUÇÃO}

O Direito tem como sua basilar função assegurar que os direitos dos indivíduos sejam respeitados tanto de forma preventiva como casuisticamente quando estes já foram desrespeitados. No tocante à última hipótese, uma dessas situações é quando ocorre a evicção. Este artigo tem por objetivo abordar a responsabilidade diante da evicção na alienação através de hasta pública por arrematação, trazendo a interpretação do ordenamento e o posicionamento da doutrina.

Com o advento do Código Civil de 2002, a matéria recebeu novo tratamento, mas apesar disso ainda existem situações que não foram abarcadas pelas mudanças, e novamente faz-se necessário o esforço doutrinário para dirimir os problemas advindos de situações não

\footnotetext{
${ }^{1}$ Artigo produzido na disciplina de Teoria Geral dos Contratos, 4ํㅗㄹ semestre / 2006, sob orientação da Prof. Rosane Leal da Silva.

${ }^{2}$ Acadêmica do $5^{\circ}$ Semestre do Curso de Direito da UFSM.

ISSN - 1981-3694

(C) 2007. Departamento de Direito da UFSM. Todos os direitos reservados.
} 
positivadas. A discussão da doutrina, antes de sua positivação, foi de enorme importância para respaldar a jurisprudência que não poderia valer-se do argumento de existir uma lacuna no ordenamento para escusar-se da análise da ocorrência dos fatos em concreto, negando prestação jurisdicional. Apesar de incansáveis discussões, e mesmo após a entrada em vigor da nova legislação civil, ainda existem inúmeros pontos controvertidos, e referentes a eles é que se encontra a relevância deste trabalho.

Primeiramente este artigo irá conceituar o instituto da evicção e a seguir o da arrematação. A partir disso, será trazida a problemática referente à responsabilidade perante os efeitos da evicção nesse tipo de alienação. Embasando-se nas diversas doutrinas, finalizase com reflexões que pretendem contribuir de alguma forma nessa questão.

\section{CONCEITO E NATUREZA JURÍDICA DA EVICÇÃO}

A evicção está presente nos casos em que um alienante transfere a posse ou propriedade de determinada coisa que não lhe pertence. Isto ocorre sem o conhecimento do adquirente, que após a realização da aquisição perde o bem por existência de um direito anterior ao momento da formalização do negócio jurídico. Essa aquisição da posse ou propriedade pode ser mediante contratos comutativos onerosos ou ainda através de hasta pública. A responsabilidade daquele que transfere a coisa é relativa aos riscos de terceiro interferir na fruição do direito ao bem, ou seja, o turbando a posse ou propriedade. O alienante deve garantir a legitimidade do direito que transfere, não podendo este conter defeito. As garantias geradas pela evicção, demonstram a preocupação do legislador de ver apreciado o princípio da boa-fé objetiva, um dos principais norteadores do Código Civil de 2002. O contratante que age com eticidade e transparência esperada por todos, ou seja, visando adquirir o bem em troca de prestação onerosa equivalente, deve ser protegido em situações em que realiza pagamento, sem receber a coisa em troca. Antes mesmo deste preceito respaldar a necessidade de tais garantias, o princípio da proibição do enriquecimento sem causa já legitimaria sua utilização, pois há pagamento indevido, ou seja, paga-se pelo bem e não se tem a contraprestação esperada (a posse ou propriedade da coisa). A correspondência de prestação e contraprestação é fator essencial em obrigações sinalagmáticas.

Tratando-se de direito disponível, a garantia pelos riscos da evicção pode ser aumentada (com estipulação de cláusula penal, fiança ou restituição em dobro, por exemplo), diminuída (retirando-se a indenização pelos frutos, por exemplo) ou ainda excluída. Tais 
possibilidades podem ocorrer somente se houver cláusula expressa, porém a exclusão integral necessita de mais requisitos. Além da cláusula que a preveja, o adquirente deve ser informado dos riscos que ameaçam a coisa e assumi-los. Se não estiverem presentes todas estas exigências a exclusão não será total, cabendo ao alienante a responsabilidade sobre o valor da coisa ao tempo da evença. Há ainda a exclusão prevista legalmente (Art.457 do CC), em que será afastada a garantia completamente em situações que o adquirente sabia que a coisa era alheia ou litigiosa, primando pelo princípio da boa-fé objetiva. Em hipóteses de exclusão integral da garantia, os contratos irão adquirir natureza aleatória, não atendendo mais ao princípio da equivalência das prestações, norteador das obrigações comutativas.

Caso o contrato não possua nenhuma cláusula de alteração de responsabilidade da indenização, esta deverá ser integral, abrangendo: a devolução do preço que foi pago pelo bem, integralmente; as despesas do contrato; os prejuízos que resultaram de forma direta da evicção; o valor das benfeitorias úteis e necessárias, não pagas, realizadas pelo evicto; o valor dos frutos que tiver sido obrigado a restituir; custas e honorários do advogado por ele constituído para defendê-lo na demanda. A responsabilidade sobre aquelas benfeitorias é originalmente do evictor e, caso este não pague, subsiste a responsabilidade sobre o alienante. $\mathrm{Na}$ hipótese das benfeitorias, úteis ou necessárias, serem realizadas pelo alienante, cabe ao evicto ressarci-las e, se não o fizer, o valor será descontado de sua indenização. Relativo às benfeitorias voluptuárias, mesmo sem previsão legal, desde que realizadas de boa-fé, tanto pelo evicto como pelo alienante, poderão ser levantadas pelo benfeitor caso não acarretem dano ao bem.

A indenização integral comporta as perdas e danos, que envolvem os danos emergentes e os lucros cessantes, esses devem ser provados materialmente para gerarem dever de indenizar. A evicção pode referir-se a todo bem ou apenas a uma parcela deste, dependendo de quanto o adquirente foi privado da coisa. A indenização referente à perda deve ser de acordo com o valor do bem ao tempo da evicção e, se esta foi parcial, deverá ser proporcional à perda sofrida. Nestes casos em que não houve perda integral, o adquirente poderá optar entre rejeitar totalmente a coisa, rescindindo o contrato e recebendo a restituição proporcional, ou ainda ficar com a coisa e receber apenas uma indenização. Estas duas hipóteses ocorrerão de acordo com a relevância do prejuízo, circunstância que deverá ser analisada pelo juiz no caso concreto. Em caso de bem alienado que não se encontra em perfeito estado ou está parcialmente destruído, subsiste a obrigação do alienante de indenizar o adquirente, salvo se esse auferiu vantagens (seguro, por exemplo) desta deterioração, ou 
ainda se a causou de forma dolosa, não sendo suficiente a simples culpa por negligência, por exemplo.

A perda do bem confirmada por sentença judicial de ação que reconhece o direito anterior de terceiro, gera o direito do evicto de voltar-se contra o alienante para receber a indenização. De acordo com a doutrina tradicional, incluindo Silvio Venosa (2002), esta é a única forma capaz de gerar os efeitos do instituto. Porém, segundo corrente jurisprudencial e doutrinária mais moderna como Pablo Stolze Gagliano e Rodolfo Pamplona Filho (2006), é possível postular as garantias contra a evicção que ocorreu através execução de ato administrativo. Uma ressalva deve ser feita: tal ato administrativo, que pode ser, por exemplo, uma apreensão policial, deve ser idôneo para acarretar perda da posse ou propriedade do bem.

Após a confirmação da perda do bem, ou seja, da evicção, o adquirente prejudicado é denominado evicto e o possuidor do direito anterior, denominado evictor. A alegação da posse ou propriedade anterior é realizada por meio de ação reivindicatória, na qual o adquirente figura como réu e aquele que alega ser possuidor ou proprietário anterior da coisa, é o autor. Para facilitar a indenização, o evictor pode utilizar-se de um tipo de intervenção de terceiro no processo, a denunciação da lide (Art. 70, inciso I do CPC), na qual o alienante ou qualquer dos anteriores poderá ingressar no processo como parte, figurando no pólo passivo juntamente com o réu. Em caso de confirmação da evicção o evicto tem direito de regresso contra o adquirente, através desse título executivo judicial.

Pela leitura do caput do art. 456 do CC, é possível entender que se não houver denunciação da lide, o réu perde o direito de argüir garantias perante o alienante. Porém, entendimento mais moderno, defendido novamente por Pablo Gagliano e Rodolfo Pamplona Filho (2006), seria afirmar que o direito subsiste e pode ser alegado através de ação autônoma. Em regra seu não exercício gera prejuízo de não se aproveitar do mesmo processo para ajuizamento da demanda regressiva. De acordo com Pablo Gagliano e Rodolfo Pamplona (2006, p. 215): “Com efeito, a obrigatoriedade de denunciação da lide é apenas para garantir, nos próprios autos da ação reivindicatória, o direito de regresso do evicto em face do alienante". A utilização da intervenção de terceiro mencionada é apenas uma facilitadora da garantia de indenização. A denunciação não é uma obrigação e sim um ônus que, se não for cumprido, gera conseqüências somente para a própria pessoa que o descumpriu, nesse caso o 
adquirente/evicto. Compartilha desse entendimento da prescindibilidade da denunciação da lide também o Superior Tribunal de Justiça ${ }^{3}$.

\section{CONCEITO E NATUREZA JURÍDICA DA ARREMATAÇÃO}

A arrematação consiste em uma das formas de transferência forçada de bens penhorados (garantidos judicialmente através de bens do executado) para satisfazer direito do exeqüente, assegurado por título executivo. É realizada por meio de alienação judicial, na qual bens precisam ser transformados em dinheiro para que se efetue o pagamento do credor. Se estes bens a serem transferidos forem imóveis, será através de praça, porém se forem móveis será por meio de leilão.

A transferência dos bens ocorre mediante pagamento de quantia certa por parte do arrematante que objetiva a propriedade destes. Quem realiza os atos executórios é o órgão jurisdicional, através da atuação direta do juiz. Caracteriza-se por uma expropriação realizada pelo Estado, um negócio jurídico bilateral. De acordo com Pontes de Miranda (1976), não é considerado um contrato. É um ato executório de direito público e natureza coativa, e dá-se em hasta pública.

A arrematação faz parte do processo de execução, e dá-se após a penhora dos bens a serem utilizados para pagamento da dívida do executado/devedor perante o exeqüente/credor. O procedimento pode ser divido em três momentos: avaliação do valor dos bens penhorados; publicização dos atos, referentes à alienação, ao público em geral, com antecedência da data da realização da hasta pública, incluindo-se intimação de interessados e do devedor (esta necessariamente pessoal); e a arrematação propriamente dita. Os dois primeiros são considerados atos preparatórios. Após a alienação é imprescindível a expedição da carta de arrematação, que comprova o direito de propriedade do arrematante. Além de outros atos, possui formalidades próprias, todo procedimento é regulado nos Arts. 686 a 707 do CPC.

Grandes divergências existem a respeito da natureza da arrematação. Dentre diversos posicionamentos, serão elencados aqueles de maior relevância para compreensão da

\footnotetext{
${ }^{3}$ Nesse sentido, decisão do STJ, REsp 880698, j. 10.04.2007, $3^{\text {a }}$ Turma, Relatora Ministra Nancy Andrighi e REsp 9552, j.25.05.1992, $3^{\text {a }}$ turma, Relator Ministro Nilson Naves.
} 
evolução da interpretação do instituto. Considerada análoga a diversas espécies de figuras jurídicas, quatro destas teorias foram principais.

A primeira delas, segundo Pontes de Miranda (1976), é a que caracterizava a arrematação como contrato privado sui generis. É a mais antiga corrente, afirmava que o juiz apenas homologava a transação entre alienante e adquirente, com natureza de um contrato eminentemente privado. A crítica que recebeu argumenta que mais do que homologar, o juiz vai além, analisando a situação das partes, exeqüente e executado, e a partir disto permite a realização da arrematação ou não.

A segunda teoria a coloca como compra e venda judicial. Dentre os que consideram a arrematação desta maneira, encontram-se os que a definem como uma gestão de negócios e os que a consideram análoga a uma representação legal.

Na primeira hipótese o vendedor é o executado e o juiz apenas age em nome deste, suprindo sua vontade. Alfredo Rocco (1962 apud MIRANDA, 1976, p. 349) foi um dos doutrinadores que defenderam essa classificação. Porém esta foi enfrentada com a alegação de que a partir do momento em que o juiz supre a vontade do alienante, não pode se falar em compra e venda, pois o executado não tem seu consentimento observado. Caso tivesse sua vontade respeitada, não haveria alienação, pois esse não deseja dispor do bem. Importante salientar que a arrematação tem como característica ser uma alienação coativa, forçada. A gestão de negócios não possui relação com este tipo de alienação, pois o executado não confere ao juiz o poder dispor de seus bens, representando-o e suprindo sua vontade, requisito básico para tornar-se gestor.

Ainda englobada pela teoria da arrematação como compra e venda encontra-se a relação feita com a representação legal de menores e incapazes, na qual o representante tutela e age de acordo com o interesse do representado.Um dos processualistas que a defendeu foi o italiano Carnelutti (1958 apud ASSIS, 1998, p. 572) Ainda muito atrelada a uma concepção privatística, recebeu crítica de Liebman (1968), o qual afirmou que o Estado age contra o interesse do executado, tendo como principal objetivo satisfazer o interesse público que, neste caso, significa a satisfação da pretensão do exeqüente em obter o pagamento da dívida. Além disso, o executado goza de plena capacidade para realizar o ato de alienação, o que descaracteriza a representação legal. O poder judiciário toma para si essa atribuição porque o alienante recusa-se a fazê-la, necessitando de prestação jurisdicional requerida pelo credor.

Uma terceira corrente doutrinária considerava este tipo de alienação uma expropriação da faculdade de dispor. É a teoria defendida por Chiovenda (1942 apud ASSIS, 
1998, p. 572), que tentou atribuir caráter de ato público à arrematação. O Estado agia expropriando o poder do executado de dispor de seus bens e não do domínio diretamente. Porém, usando dessa faculdade, vende os bens. A crítica em relação a esta teoria veio novamente de Liebman(1968) que analisou que o Estado deixaria de transferir diretamente o bem do devedor para o arrematante. $\mathrm{O}$ jurista não encontrou justificativa para tal, pois tendo com resultado final expropriação do bem, não há razão para conferir ao Estado apenas a atribuição de expropriar a faculdade de dispor.

Por fim, o entendimento mais aceito atualmente é o que classifica a arrematação como expropriação do bem. Esse segmento da doutrina tem como expoentes tanto juristas da atualidade, como Humberto Teodoro Júnior (2005), quanto vanguardistas, como Paula Baptista (1930 apud MIRANDA, 1976, p. 347), que a defendeu em meados do Século XIX. Porém sem dúvida nenhuma Liebman (1968) foi um dos principais responsáveis por sua aceitação. Tal teoria afasta a natureza contratual da arrematação. Efetua-se a expropriação do domínio. O órgão judicial expropria o bem do executado diretamente, repassando-o para o arrematante e converte o valor pago por este para atender a pretensão do exeqüente. Sendo a arrematação um meio executório para este fim, não possui um objetivo em si mesmo, caso contrário seria uma compra e venda judicial.

No próximo item será feita uma abordagem comparativa entre o diploma civil de 1916 e de 2002.

\section{TRATAMENTO DA MATÉRIA PELO CÓDIGO CIVIL DE 1916 E PELO CÓDIGO CIVIL DE 2002}

De acordo com o Art. 1.107 do CC/16, somente era assegurada a responsabilidade do alienante perante os riscos da evicção nos contratos onerosos. Tal previsão não determinava as mesmas garantias para bens adquiridos em hasta pública, visto que esse tipo de aquisição não se enquadrava naquela classificação. O silêncio do legislador gerou inúmeras discussões a respeito dessa possibilidade e, diante desta lacuna, doutrina e jurisprudência esforçaram-se para encontrar uma solução. As divergências eram muitas, porém a opinião mais aceita veio a ser confirmada pelo novo diploma civil.

No Art. 447 in fine do CC/02 foi acrescentado que, mesmo em bens adquiridos em hasta pública, subsiste a responsabilidade do alienante perante os riscos da evicção. Porém, mesmo com esta previsão, permaneceram algumas discussões referentes sobre quem irá recair 
a responsabilidade em tais casos. Embora tal dispositivo aplique-se a qualquer dos casos de aquisição através de hasta pública, a abordagem será limitada somente ao principal exemplo, a arrematação.

Liebman (1968) e grande parte da doutrina processualista nacional, considerava que não era possível falar-se em evicção propriamente dita em bens adquiridos através da arrematação, pois essa garantia somente admitia-se às alienações contratuais onerosas, porém, poderia ser aplicada garantia similar. Com o advento do Código Civil de 2002 atribui-se a evicção mesmo que os bens fossem adquiridos em hasta pública, pondo fim à discussão.

A seguir será feita uma análise da responsabilidade de cada um dos participantes da arrematação, além da possível responsabilidade do Estado.

\subsection{Responsabilidade do executado e do exeqüente perante o evicto}

$\mathrm{O}$ adquirente que perde o bem arrematado por evicção deve ter seus prejuízos ressarcidos. Variados posicionamentos foram defendidos, a respeito da responsabilidade do executado e exeqüente, tanto no direito comparado como na doutrina nacional.

Segundo o entendimento de Chiovenda (1945 apud ASSIS, 1998, p. 578), o executado/devedor não era responsável pela eviç̧ão, pois este não alienou por vontade própria, pois o Estado expropria sua faculdade de dispor de seus bens, considerando a arrematação uma venda judicial em que o executado não era o vendedor. Diante disto, a responsabilidade recai sobre o exeqüente no limite do valor do preço recebido.

Aos que consideravam a arrematação um contrato de compra e venda, entre eles Carnelutti(1958 apud SANTOS, 1998, p. 341), o devedor era considerado o vendedor e, portanto, respondia pela evicção e, caso estivesse insolvente, o responsável passaria a ser o exeqüente.

Com entendimento divergente do predominante hodierno, existem aqueles que defendem que o exequiente só seria responsável em situações nas quais agiu com ardil, insidiosamente. Caso contrário, não deve responder por situação que não teve intenção de criar, sendo que somente almeja ver sua pretensão de pagamento atendida, e apenas por este motivo, precisou ingressar com a demanda, já que houve o inadimplemento do devedor. Nesse sentido estão Pablo Gagliano e Rodolfo Pamplona (2006).

Mesmo antes de previsão legal, majoritariamente doutrina e jurisprudência admitiam a responsabilidade perante o adquirente, nos casos em que este perde o direito ao bem por existir uma causa anterior à arrematação. $O$ devedor responde pela evicção e, 
subsidiariamente, o exeqüente, em casos de insolvência do primeiro. A responsabilidade do devedor é justificada pelo princípio da proibição do enriquecimento sem causa, pois este teve sua dívida saldada por terceiro que não havia contraído-a (adquirente) e através de patrimônio que não lhe pertencia (pertencente ao evictor). A garantia devida pelo credor encontra respaldo no mesmo princípio, diante de explicação que admite que, apesar de possuir direito de receber o pagamento da dívida, esse não poderá ser realizado através da alienação de bens de terceiro (evictor). Importante salientar que a responsabilidade do exeqüente é no limite do valor que o adquirente pagou.

Defende-se que a responsabilidade deve subsistir independentemente da intenção, pois o valor pago pelo arrematante foi indevido, não cabia a ele, ou seja, a obrigação a ser satisfeita perante o exeqüente não lhe pertencia. $O$ credor deve devolver o valor do pagamento. Mesmo que o exeqüente tenha agido de boa-fé, não há como eliminar sua responsabilidade, sob pena de ocorrer um claro caso permissivo para o enriquecimento ilícito.

\subsection{Responsabilidade do Estado perante o evicto}

Para uma corrente doutrinária, na qual se encontra Araken de Assis (1998) e Fredie Didier Jr.(2004), o Estado pode ser responsabilizado de forma solidária, juntamente com o executado e o exeqüente. Eles utilizam como argumento que o poder estatal coordena todo o procedimento do processo de execução, incluindo-se a arrematação, sob sua tutela jurisdicional. O Estado é legitimado para penhorar e expropriar bens do executado em troca de título oneroso equivalente, e posteriormente decidir que o bem arrematado pertencia à terceiro - na hipótese de evicção - anteriormente à alienação coativa. Portanto, possui todos os poderes referentes à disposição dos bens e à atribuição a quem pertence o direito sobre os mesmos e, portanto, deve ser responsabilizado por seus atos de poder público. Para Araken de Assis (2002, p. 741): “[...] o Estado assume o risco de entregar com uma mão o que, em seguida, retirará com a outra. Daí exsurge o dever estatal de indenizar o evicto".

Todavia, mesmo que tal posicionamento tenha uma boa justificativa - dar maior segurança ao adquirente diante da evicção - a responsabilidade impingida ao Estado é exagerada. Essa afirmação justifica-se pelo fato que, a partir do momento que se estipula tal obrigação, cria-se precedente para imputar-lhe responsabilidade em todo e qualquer ato jurisdicional. Admitir tal possibilidade seria criar para o Estado praticamente uma responsabilidade objetiva - na qual culpa ou dolo na situação são irrelevantes - sobre seu dever de prestar jurisdição. Obrigação esta que não seria comportada pelos cofres públicos, 
visto que a prestação jurisdicional do país apresenta inúmeros problemas, muitas vezes mais graves que este em tela. Todos esses problemas requerem uma reforma ampla e estrutural e não mera solução imediatista e patrimonial, que se somaria a mais uma das obrigações estatais não cumpridas.

Nesse sentido, Pablo Gagliano e Rodolfo Pamplona (2006) não admitem a responsabilidade estatal na hipótese de ter realizado-se todo procedimento de execução devidamente. Para eles, o Estado apenas cumpriu seu dever constitucional, através de órgão jurisdicional, de apreciar toda lesão ou ameaça de lesão a direito, presente no Art. $5^{\circ}$, inciso XXXV da CF.

Referente à responsabilidade estatal, Pablo Gagliano e Rodolfo Pamplona Filho (2006, p. 205) consideram que "[...] ampliar o âmbito de garantia contra os riscos da evicção sem norma legal autorizadora soa como um superdimensionamento do instituto", defendendo um posicionamento positivista, no qual não se admite responsabilização pela evicção por quem a lei não obrigou.

\section{CONSIDERAÇÕES FINAIS}

A arrematação, ato executório de direito público pelo qual expropriam-se bens coativamente para prestação de execução jurisdicional, é uma das várias formas de se adquirir um bem. Logo, também é passível de ser um meio pelo qual um alienante pode valer-se para dispor de um bem que não lhe pertence para obter locupletamento indevido. Diante de tal situação, através de sentença judicial ou ato administrativo idôneo, é possível reconhecer o instituto da evicção. Porém, antes do $\mathrm{CC} / 02$ não havia dispositivo legal que garantisse a responsabilidade pela evicção perante o adquirente/evicto. Antes deste diploma civil, muitas discussões que ocorreram a respeito da possibilidade de tal garantia perduram até hoje, visto que só é positivada a responsabilidade do devedor/executado, sendo colocadas à margem a responsabilidade do credor/exeqüente e do Estado.

Para assegurar uma indenização mais célere, o evicto pode valer-se da denunciação da lide, esta se caracterizando como um ônus e não uma obrigação. Logo, se não for utilizada, ainda subsiste a possibilidade de buscar a indenização através de ação autônoma.

Entende-se que o executado e o exeqüente, este subsidiariamente, respondem pela evicção, baseado no princípio da proibição do enriquecimento sem causa. Porém a responsabilidade do Estado diante da evicção em bem adquirido em hasta pública seria uma 
obrigação além de suas possibilidades e que não lhe compete, visto que ele não aufere nenhum proveito diante da situação e, portanto, não se enquadraria no caso de enriquecimento sem causa. Somando-se a isso, abriria discussão para indenizar em todo tipo de prestação jurisdicional, solução pouco viável para a capacidade dos cofres públicos.

A indenização nos casos da evicção é extremamente importante, atendendo a princípios como o da boa-fé objetiva e o da equivalência das prestações, além do que gera uma maior tranqüilidade para adiquirir-se bens através da arrematação, que de certa forma é um dos instrumentos do Estado que colaboram com a prestação jurisdicional.

\section{REFERÊNCIAS BIBLIOGRÁFICAS}

ASSIS, Araken de. Manual do Processo de Execução. $5^{a}$ Ed. São Paulo: Revista dos Tribunais, 1998.

ASSIS, Araken de. Manual do Processo de Execução. $8^{a}$ Ed. São Paulo: Revista dos Tribunais, 2002.

BRASIL. Constituição Federal. Código Civil. Código de Processo Civil. Código Comercial. Organização por Yussef Said Cahali. São Paulo: Revista dos Tribunais, 2007.

GAGLIANO, Pablo Stolze; FILHO, Rodolfo Pamplona. Novo Curso de Direito Civil. $2^{\mathrm{a}}$ Ed. São Paulo: Saraiva, 2006. V. 4: Contratos.

JUNIOR, Fredie Didier. Regras Processuais no Código Civil: aspectos da influência do Código Civil de 2002 na legislação processual. $2^{\text {a }}$ Ed. São Paulo: Saraiva, 2004.

JUNIOR, Humberto Theodoro. Curso de Direito Processual Civil. Ed. 38 ${ }^{\text {. }}$ Rio de Janeiro: Forense, 2005. V.2: Processo de Execução e Processo Cautelar.

LIEBMAN, Enrico Tullio. Processo de Execução. $3^{\text {a }}$ Ed. São Paulo: Saraiva, 1968.

MIRANDA, Francisco C. Pontes de. Comentários ao Código de Processo Civil. $1^{\text {a }}$ Ed. Rio de janeiro: Forense, 1976. Tomo X.

RIZZARDO, Arnaldo. Contratos. $6^{\text {a }}$ Ed. Rio de Janeiro: Forense, 2005.

SANTOS, Moacyr Amaral. Primeiras Linhas de Direito Processual Civil. $17^{\text {a }}$ Ed. São Paulo: Saraiva, 1998.

VENOSA, Sílvio de Salvo. Direito Civil. $3^{\text {a }}$ Ed. São Paulo: Atlas, 2002. V.2: Teoria Geral das Obrigações e Teoria Geral dos Contratos.

WAMBIER, Luis Rodrigues. Curso Avançado de Processo Civil. $7^{a}$ Ed. São Paulo: Revista dos Tribunais, 2005. V.2: Processo de Execução. 
Novembro de 2006 - Vol. 1, N. 3, p 55-66

66 